\title{
Releasing Tensin
}

Myofibroblasts are reparative cells tasked with the synthesis, secretion, deposition, and remodeling of extracellular matrix (ECM). In the context of normal wound repair, myofibroblasts function as necessary effectors contributing to an integrated response aimed at restoring tissue homeostasis. In the lungs, the successful repair response culminates with restoration of an intact alveolar epithelium, degradation of excessive ECM, and clearance of myofibroblasts via apoptosis, leaving behind a physiologic scar that does not impair lung function (1). In contrast, the pathologic scar formation that is evident in fibrotic lung diseases such as idiopathic pulmonary fibrosis is characterized, in part, by the aberrant persistence of myofibroblasts. These rogue myofibroblasts fail to respond to normal environmental cues to shut down and instead, similar to cancer cells, become autonomous drivers of the pathologic response (2).

Our understanding of the mechanisms that underlie fibroblast acquisition of this aberrant phenotype continues to evolve. Importantly, it is possible that these mechanisms change over time and that the mechanisms that initially stimulate myofibroblast recruitment and activation are not required for their survival and persistent activation. Transforming growth factor $\beta 1$ (TGF- $\beta 1$ ), for example, is well recognized for its ability to induce profibrotic myofibroblast phenotypes in vitro and fibrosis in vivo. However, it has also become evident that biomechanical and biochemical signals derived from the ECM itself can independently regulate myofibroblast phenotype and function (3-5). Thus, delineating the mechanisms of mechanotransduction, by which fibroblasts convert environmental cues from the ECM into the intracellular signals that modulate their function is crucial to advancing our mechanistic understanding of fibrosis and holds promise for the development of novel interventions.

MKL-1 (megakaryoblastic leukemia-1, also known as Myocardin Related Transcription Factor-A/MRTF-A) is a transcriptional co-activator that is, in quiescent fibroblasts, bound to globular actin (G-actin) and sequestered in the cytoplasm. Under circumstances that stimulate actin polymerization, as seen with exposure to TGF- $\beta$ or rigid extracellular matrices, MKL- 1 is released from G-actin and imported into the nucleus, where it partners with serum response factor to drive transcriptional responses (6). These responses have been strongly linked to profibrotic fibroblast function, as MKL-1 has been shown to mediate fibroblast differentiation, resistance to apoptosis, collagen and fibronectin synthesis, and plasminogen activator inhibitor-1 production (6-8). In several murine models, genetic deficiency in MKL-1 and pharmacologic inhibition of MKL-1 signaling have diminished lung fibrosis (8-10).

Tensin1 (TNS1) is a scaffold protein that has been linked to the formation of fibrillary fibronectin matrices and mechanotransduction signaling through its interactions with integrin $\beta 1$ and protein kinases that localize to cellular focal adhesions, including focal adhesion kinase (FAK). In this issue of the Journal, Bernau and colleagues (pp. 465-476) demonstrate a link among TGF- $\beta 1-$ mediated myofibroblast differentiation, matrix production, and MKL-1-dependent transcriptional regulation of TNS1 (11). The investigators show that TGF- $\beta 1$ increases TNS1 expression in normal lung fibroblasts and that TNS1 is robustly expressed within the fibroblastic foci of idiopathic pulmonary fibrosis tissue. Moreover, TNS1 mRNA and protein levels are increased in explanted fibroblasts from idiopathic pulmonary fibrosis lungs in comparison to cells from control lungs. Interestingly, although the TGF- $\beta 1$-induced increase in TNS1 is associated with myofibroblast differentiation, the disruption of canonical Smad-mediated TGF- $\beta 1$ prevented the increased $\alpha$-SMA expression associated with myofibroblast differentiation without affecting TNS1, demonstrating that TNS1 is regulated by non-Smad signaling downstream of the TGF- $\beta$ receptors. Implicating MKL-1 in the regulation of TNS1, disruption of actin polymerization prevented an increase in TNS1, whereas induction of actin polymerization with Jasplakinolide was sufficient to promote increases in TNS1. Loss-of-function studies using pharmacologic and/or genetic approaches to inhibit or knockdown MKL- 1 prevented TGF- $\beta 1$ - and Jasplakinolide-mediated induction of TNS1, confirming the mechanistic association between actin polymerization, MKL-1 nuclear localization, and TNS1 expression.

Given that TGF- $\beta 1$-induced myofibroblast differentiation was Smad-dependent, whereas TNS1 induction was Smad-independent, it was somewhat surprising that knockdown of TNS1 prevented myofibroblast differentiation and ECM expression in response to TGF- $\beta$. To address this, the authors show that knockdown of TNS1 also prevented FAK phosphorylation by TGF- $\beta 1$. Previous studies have shown that FAK phosphorylation by TGF- $\beta 1$ is Smaddependent and is critical for myofibroblast differentiation $(12,13)$. Taken together, these data suggest that myofibroblast differentiation requires the integration of both Smad-dependent and Smad-independent signaling downstream of the TGF- $\beta$ receptor complex. Further studies to delineate the Smadindependent mechanisms involved in TNS1 regulation, and how these Smad-independent pathways affect fibroblast phenotypes, are needed.

This manuscript demonstrates a mechanistic hierarchy by which actin polymerization promotes MKL-1-dependent transcription of TNS1, which is necessary for FAK phosphorylation, focal and fibrillar adhesion formation, and myofibroblast differentiation. In addition to understanding the non-Smad-dependent signaling mechanisms, several questions regarding the regulation of TNS1 and its role in fibroblast phenotypes and fibrosis remain to be examined. For example, the role of matrix biomechanics remains unclear. The experiments in this study were done on rigid substrates suggesting that the fibroblasts were already "skewed" toward a myofibroblast phenotype. This begs the question of the role of TNS1 in the regulation of fibroblast phenotypes on more compliant matrices, and whether a "stiff" matrix is necessary for the phenotypic responses detailed in this publication. A priori evidence supporting this pathway in the development of lung fibrosis (before the 
establishment of the rigid substrate that characterizes lung fibrosis) is provided by studies showing that MKL1 knockout mice are protected from lung fibrosis $(9,10)$. However, in vivo studies defining a role for TNS1 in developing and established fibrosis are necessary.

Studies have established roles for the proteins that regulate and interact with TNS1, such as MKL-1 and FAK, as essential contributors in lung fibrosis $(8-10,14-16)$. Thus, it remains to be determined whether TNS1 has a unique role in the regulation of fibroblast phenotype such that this scaffolding protein might present a specific target for antifibrotic therapy. Other transcriptional co-activators, such as those in the Hippo pathway (17), have also been linked to fibroblast phenotypes and fibrosis; it remains to be determined whether TNS1 represents a convergence point for multiple profibrotic pathways or whether its role is limited to the TGF- $\beta /$ MKL- 1 pathway. There continues to be an urgent need for the development of novel effective therapies to treat patients with lung fibrosis. Further studies are necessary to determine whether TNS1 is a viable target.

Author disclosures are available with the text of this article at www.atsjournals.org.

Jeffrey C. Horowitz, M.D.

Division of Pulmonary and Critical Care Medicine

University of Michigan Medical School

Ann Arbor, Michigan

ORCID ID: 0000-0002-1505-2837 (J.C.H.).

\section{References}

1. Glasser SW, Hagood JS, Wong S, Taype CA, Madala SK, Hardie WD. Mechanisms of lung fibrosis resolution. Am J Pathol 2016;186: 1066-1077.

2. Horowitz JC, Osterholzer JJ, Marazioti A, Stathopoulos GT. "Scarcinoma": viewing the fibrotic lung mesenchymal cell in the context of cancer biology. Eur Respir J 2016;47:1842-1854.

3. Thannickal VJ, Henke CA, Horowitz JC, Noble PW, Roman J, Sime PJ, Zhou Y, Wells RG, White ES, Tschumperlin DJ. Matrix biology of idiopathic pulmonary fibrosis: a workshop report of the national heart, lung, and blood institute. Am J Pathol 2014;184:1643-1651.

4. Tschumperlin DJ. Matrix, mesenchyme, and mechanotransduction. Ann Am Thorac Soc 2015;12:S24-S29.
5. Parker MW, Rossi D, Peterson M, Smith K, Sikström K, White ES, Connett JE, Henke CA, Larsson O, Bitterman PB. Fibrotic extracellular matrix activates a profibrotic positive feedback loop. J Clin Invest 2014;124:1622-1635.

6. Riches DW, Backos DS, Redente EF. ROCK and Rho: promising therapeutic targets to ameliorate pulmonary fibrosis. Am J Pathol 2015;185:909-912.

7. Sandbo N, Kregel S, Taurin S, Bhorade S, Dulin NO. Critical role of serum response factor in pulmonary myofibroblast differentiation induced by TGF- $\beta$. Am J Respir Cell Mol Biol 2009;41:332-338.

8. Sisson TH, Ajayi IO, Subbotina N, Dodi AE, Rodansky ES, Chibucos LN, Kim KK, Keshamouni VG, White ES, Zhou Y, et al. Inhibition of myocardin-related transcription factor/serum response factor signaling decreases lung fibrosis and promotes mesenchymal cell apoptosis. Am J Pathol 2015;185:969-986.

9. Bernau K, Ngam C, Torr EE, Acton B, Kach J, Dulin NO, Sandbo N. Megakaryoblastic leukemia-1 is required for the development of bleomycin-induced pulmonary fibrosis. Respir Res 2015;16:45.

10. Zhou Y, Huang X, Hecker L, Kurundkar D, Kurundkar A, Liu H, Jin TH, Desai L, Bernard K, Thannickal VJ. Inhibition of mechanosensitive signaling in myofibroblasts ameliorates experimental pulmonary fibrosis. J Clin Invest 2013;123:1096-1108.

11. Bernau K, Torr EE, Evans MD, Aoki JK, Ngam CR, Sandbo N. Tensin 1 is essential for myofibroblast differentiation and extracellular matrix formation. Am J Respir Cell Mol Biol 2017;56:465-476.

12. Horowitz JC, Rogers DS, Sharma V, Vittal R, White ES, Cui Z, Thannickal VJ. Combinatorial activation of FAK and AKT by transforming growth factor- $\beta 1$ confers an anoikis-resistant phenotype to myofibroblasts. Cell Signal 2007;19:761-771.

13. Thannickal VJ, Lee DY, White ES, Cui Z, Larios JM, Chacon R, Horowitz JC, Day RM, Thomas PE. Myofibroblast differentiation by transforming growth factor- $\beta 1$ is dependent on cell adhesion and integrin signaling via focal adhesion kinase. J Biol Chem 2003;278: 12384-12389.

14. Ding Q, Cai GQ, Hu M, Yang Y, Zheng A, Tang Q, Gladson CL, Hayasaka $\mathrm{H}$, Wu H, You Z, et al. FAK-related nonkinase is a multifunctional negative regulator of pulmonary fibrosis. Am J Pathol 2013;182:1572-1584.

15. Lagares D, Busnadiego O, García-Fernández RA, Lamas S, RodríguezPascual F. Adenoviral gene transfer of endothelin-1 in the lung induces pulmonary fibrosis through the activation of focal adhesion kinase. Am J Respir Cell Mol Biol 2012;47:834-842.

16. Vittal R, Horowitz JC, Moore BB, Zhang H, Martinez FJ, Toews GB, Standiford TJ, Thannickal VJ. Modulation of prosurvival signaling in fibroblasts by a protein kinase inhibitor protects against fibrotic tissue injury. Am J Pathol 2005;166:367-375.

17. Liu F, Lagares D, Choi KM, Stopfer L, Marinković A, Vrbanac V, Probst CK, Hiemer SE, Sisson TH, Horowitz JC, et al. Mechanosignaling through YAP and TAZ drives fibroblast activation and fibrosis. Am J Physiol Lung Cell Mol Physiol 2015;308:L344-L357. 